\title{
REFLECTIONS ON 50 YEARS OF COMPUTING: IMPACT OF PROFESSIONALISM ON TEACHING, PRACTICE AND RESEARCH
}

\section{T. William Olle}

T. William Olle Associates, GB

\section{Introduction}

Fifty five years ago, in 1953, many aspects of computing were not even invented. Even the idea of making a career out of computing was essentially unknown. There were no formal courses for students to attend, no lecturers to teach the courses, practitioners were mainly researchers in universities and government establishments, and programming was a tool for researchers in subjects other than computing. In other words, there were no computer professionals.

In 2008 , computing - be it teaching, practice or research - is a major employer of many skilled persons. It is recognized that computers play a significant role in all facets of human endeavour, from toys to jumbo jets, from corner shop businesses to multinational corporation and from children to senior citizens.

This paper examines the dimensions of the "impact of professionalism" and attempts to stimulate more attention on professionalism from the various communities involved, but particularly from the research community. 


\section{Dimensions of professionalism in computing}

Professionalism in computing has many dimensions. One is the simple trichotomy - practitioners, teachers and researchers, although many would subsume the last two under the first.

A perspective on sibling professions (namely other than computing) is very important.

Lawyers and doctors have been around a long time and their professional status is centuries old. Accountancy and engineering are more recent.

Another dimension is based on some kind of taxonomy of the total field. The body of knowledge in computing is ever changing and at the same time ever increasing. Emphasis on specialisms which can be a basis for professionalism is needed.

Next, the problem of grading (within a specialism, within each of the three above referenced parts of the trichotomy) must also be considered.

Each of these four "dimensions" will now be discussed in turn.

\section{Simple trichotomy}

The trichotomy of practitioner, researcher, teacher (sequence deliberately alphabetical) is useful when considering the impact of professionalism. A practitioner in the computing field might always claim he or she is a professional - possibly only in the sense of a sports person that the person is not an amateur. Anyone who expects remuneration for their work might regard themselves as professional. However, the question of recognized qualifications is surely paramount here. If the qualification claimed comes from a university then the issue can be interpreted as to whether that qualification is recognized. 
The problem of acceptability of a qualification for a professional recognition even goes further. Some practitioner employment positions may well require no more than a secondary school qualification. Should such positions and those holding them be regarded as "professional" or should some other term be used?

Moving from practitioner to researcher, it seems appropriate to assert that a researcher should have at least the qualifications of a professionally recognized practitioner. Since research into computing related topics should really have some kind of practical link, it may be unnecessary to consider professionalism for researchers as different from professionalism for practitioners.

The final member of the trichotomy is teachers, arguably the most critical when it comes to consideration of professionals.

Teachers are required to train practitioners to become professionals in the computing field. Therefore the teachers themselves must have reached at least the same professional standards as those they are trying to inculcate into their students.

Finally, it should be noted that in tertiary education generally, researchers are expected to teach although the converse may not always be true.

For convenience, this paper refers to all members of this trichotomy as "computing practitioners".

\section{Sibling professions}

\subsection{Legal profession}

It is not clear which branch of professionalism should be noted as the pioneers but it is probably the legal profession. The London Law Society was founded in 1825 [1 ]. It may well have been formed following a lead established in other countries.

The American Bar Association has published a 21 item list of the "model rules of professional conduct" [2]. It is not clear that this list could serve as a basis for rules in the computer profession. 


\subsection{Medical profession}

Computing is a fairly recent arrival in the world of professionalism. The British Medical Association claims it was established in 1832 [3].

The following extract from paper by David Morell in the February 2003 edition of the Catholic Medical Quarterly [4] is of interest to any consideration of professionalism.

1. The professional has skills or expertise proceeding from a broad knowledge base.

2. The professional provides a service based on a special relationship with those whom he or she serves. This relationship involves a special attitude of beneficence tempered with integrity. This includes fairness, honesty and a bond based on legal and ethical rights and duties authorised by the professional institution and legalised by public esteem.

3. To the extent that the public recognises the authority of the professional, he or she has the social function of speaking out on broad matters of public policy and justice, going beyond duties to specific clients.

4. In order to discharge these functions, professionals must be independent of the influence of the State or commerce.

5. The professional should be educated rather than trained. This means having a wide cognitive perspective, seeing the place of his or her skills within that perspective and continuing to develop this knowledge and skills within a frame work of values.

6. A professional should have legitimised authority. If a profession is to have credibility in the eyes of the general public, it must be widely recognised as independent, disciplined by its professional association, actively expanding its knowledge base and concerned with the 
education of its members. If it is widely recognised as satisfying these conditions, then it will possess moral as well as legal legitimacy, and its pronouncements will be listened to with respect.

The question should be asked whether any part of this definition is irrelevant in the world of computing professionalism.

Another aspect of professionalism in the world of medicine surely comes from the 170 years that they have been organized. This aspect is specifically the breakdown of a vast body of knowledge and associated competence into recognized specialist areas.

A few examples in the medical profession are bacteriology, cardiology, paediatrics, pathology, oncology, orthopaedics.

This illustration of a breakdown of a body of knowledge is of significant interest to professionalism in computing where there is also a vast body of knowledge. However, one can argue that any taxonomy of computing which might have been the cornerstone for a breakdown 20 years ago would today be largely obsolete. Not only is the body of knowledge in computing vast, it is also highly volatile.

This is not intended to argue against a breakdown, but rather to emphasize the importance of choosing the components carefully and to prefer those which will stand the test of time.

\subsection{Accounting profession}

It is important to distinguish the origins of accounting from the origins of the accounting profession. It is asserted in [6] that accounting can trace its origins to the Italian Renaissance.

The accounting profession is arguably closer to the computing profession than is either the medical or legal professions. For one thing, much of what accountants produce makes use of computing systems and resources and has done so for several of the decades during which computers have been available. The early business uses of computers focussed inevitably on accounting applications. This was preceded by the punched card machinery which pre-dated 
the advent of stored program computers.

The emergence of a professional accounting society is harder to pinpoint than for the legal and medical professions [6]. Apparently, the first professional body in accounting was in Edinburgh Scotland in 1853.

There were clear driving forces for the setting up of the accounting profession. One was the Companies Act passed in the UK in 1852. The literature emphasizes two aspects namely accounting standards and ethics. In the computer field, standards are very important but it would be hard to assert that the computing profession is built around them. Ethics are important in any profession. The accounting profession experienced considerable shock in 2003 in the aftermath of the Enron scandal. This kind of event could easily happen in the computing profession.

\title{
5. Emphasis on specialisms
}

Each of the three sibling professions considered above is partitioned into a set of specialisms. In the case of accounting and legal professions, to which the practice of the profession applies, such factors for partitioning are the areas of application which are not necessarily specific to the profession. This is best illustrated by identifying some specific areas for the accounting profession as follows:

\author{
Charity and Voluntary, \\ Entertainment and Mechanical, \\ Health Care \\ Tourism and Hospitality \\ Public Sector \\ Farming and Rural.
}

One can argue that any application area which needs accounting services, also needs computing services (and may possibly need legal expertise).

This raises the question whether a taxonomy of computing specialisms should include a taxonomy of application areas in which 
the computing is applied. However, many applications of computers cross specialisms. Some simple examples are

Payroll (varies from country to country according to legislation)

Accounting (or finance generally)

Stock control

Banking

Sales

These examples may be contentious in that the idea of designating computer professionals as trained in one of these fairly common well recognized specialisms may seem too simplistic. The question which needs to be addressed is "how is it possible to package parts of computing in a way which is generally acceptable to those who wish to employ a practitioner in computing?".

Another aspect of computing which merits consideration is the irrefutable fact the computing has evolved during a period in history when communication (and indeed labour movement) between countries has been more prevalent than ever before.

Professionalism in the three sibling areas considered in this paper goes back many decades, in some cases to an era before the availability of the telephone. Computing on the other hand has evolved during an era when travel and labour movement generally have been the norm rather than the exception!

This aspect of the problem presents the following challenge for computing professionals. The formulation and introduction of a computing profession should as far as possible take place in an international milieu rather than a national one. This would certainly make the task harder but the ultimate rewards would appear to justify this kind of approach.

\section{Way forward}

Even on the basis of this brief paper, it is possible to note a number of steps which are already being followed. It is important to build on the work already undertaken [7] in the IFIP International Professional Practice Programme (I3P). The main thrust of this 
report has been summarized in a paper by Charles Hughes [8]. These two papers give a clear direction for the role of IFIP in developing what is rapidly (and indeed commendably) being identified as the information technology profession. The term is clearly broader and more apposite than older terms such as
Data processing
Information processing
Computer science
Informatics

Information technology can be taken as subsuming all of these.

The recent one page article [9] on "Advancing the IT Profession" stresses achieving the prestige associated with the three established professions reviewed briefly in this paper, namely law, accountancy and medicine. It also emphasizes the importance of "raising public awareness of the vital role of IT in our modern world.

One aspect of professionalism which these three references ([7], [8] and [9]) do not touch on is the importance of promoting a workable taxonomy (or classification scheme) for the IT profession. The problem is not that such schemes exist but that there are too many of them. These vary both nationally and linguistically.

Since its early inception, IFIP itself has always had a traditional breakdown into "Technical Committees". However the motivation for this partitioning has been based more on technical interest rather than the promotion of career paths and researchable topics.

The use of Special Interest Groups within many of the larger and more active national societies can be regarded in a similar manner to the breakdown into IFIP technical committees.

It is clear that any taxonomy of IT for professional purposes should at least take into account both application areas (clearly overlapping) such as finance, personnel, manufacturing, science, transport) and inherent IT aspects each of which crosses several application areas. 


\section{References}

[1] www.lawsociety.org.uk/aboutlawsociety/whoweare/abouthistory.law

[2] www.abanet.org/cpr/mrpc/home.html

[3] www.bma.org.uk/ap.nsf/Content/HubhistoryoftheBMA

[4] www.catholicdoctors.org.uk/CMQ/2003/Feb/what-is-professionalism.htm

[5] www.icaew.com/index.cfm?route $=155691$

[6] http://acct.tamu.edu/giroux/Shorthistory.html

[7] First Report of IFIP Professional Practice Task force January 2007 profess sional practice programme. C.Hughes. Invited paper WCC2008.

[9] Advancing the IT Profession. IFIP News March 2008. 